This item was submitted to Loughborough's Research Repository by the author.

Items in Figshare are protected by copyright, with all rights reserved, unless otherwise indicated.

\title{
The effect of psychosocial factors on perceptions of driver education using the goals for driver education framework
}

PLEASE CITE THE PUBLISHED VERSION

PUBLISHER

Elsevier

VERSION

AM (Accepted Manuscript)

\section{PUBLISHER STATEMENT}

This paper was accepted for publication in the journal Transportation Research Part F: Traffic Psychology and Behaviour and the definitive published version is available at https://doi.org/10.1016/j.trf.2019.09.004.

\section{LICENCE}

CC BY-NC-ND 4.0

\section{REPOSITORY RECORD}

Bates, Lyndel, Alana Hawkins, David Rodwell, Levi Anderson, Barry Watson, Ashleigh Filtness, and Grégoire Larue. 2019. "The Effect of Psychosocial Factors on Perceptions of Driver Education Using the Goals for Driver Education Framework”. figshare. https://hdl.handle.net/2134/9778307.v1. 
3 Lyndel Bates $^{a *}$, Alana Hawkins ${ }^{b}$, David Rodwell ${ }^{b}$, Levi Anderson ${ }^{a}$, Barry

4 Watson $^{\mathrm{b}}$, Ashleigh J. Filtness ${ }^{\mathrm{c}}$ \& Grégoire S. Larue ${ }^{\mathrm{b}}$

5 a School of Criminology and Criminal Justice and Griffith Criminology Institute, Griffith

6 University, Brisbane, Australia

$7 \quad{ }^{\mathrm{b}}$ Centre for Accident Research and Road Safety - Queensland (CARRS-Q), Institute for Health

8 and Biomedical Innovation, Queensland University of Technology, Brisbane, Australia

9 ' Design School, Loughborough University, Loughborough, Leicestershire, UK

10

$11 *$ Corresponding Author

12 Email: I.bates@griffith.edu.au

Phone: 61737351429

14

Revised version submitted to Transportation Research Part F: Traffic Psychology and 
Professional driver education and training has often been found in evaluations to not provide additional safety benefits for young drivers. However, it is possible that identifying how psychosocial factors affect perceptions of driver education may contribute to improve program design, content and implementation. The Goals for Driver Education (GDE) framework was used in this research to explore the impact of various psychosocial factors, such as sensation seeking, normlessness, attitudes towards driver risk taking and positive attitudes towards speeding on the perceptions of young drivers participating in a professional driver education courses. One hundred and fourteen young drivers $\left(M_{\text {age }}=17.89, S D=0.85\right.$ ) who had attended a driver education course within the past three years completed an online survey that collected socio-demographic information, perceptions of the benefits of education for individuals learning to drive at each level of the GDE framework, and information about psychosocial factors. Overall, the results suggested that psychosocial factors do affect young driver perceptions of driver education and training. Higher levels of sensation seeking predicted that participants thought it beneficial for novice driver education to focus on vehicle manoeuvring (Level 1), mastery of traffic situations (Level 2) and goals and contexts for driving (Level 3) but not the highest level of the GDE matrix, goals for life. Higher levels of normlessness predicted participants believing it was more beneficial for new drivers to learn about the goals and contexts for driving. This suggests there is a need for driver educators to consider personalising their programs as much as possible to take into account the psychosocial differences between individuals, which may impact on the way they respond to the education they receive.

Keywords: Young drivers; Gadget matrix; Sensation seeking; Driver training; Driver education; Goals for Driver Education

Acknowledgements: This research was supported by the Australian Government through the Australian Research Council's Linkage Projects funding scheme (LP140100409). The authors thank Roadcraft Driver Education and their Chief Executive Officer, Ms Sharlene Makin, for their assistance with recruitment.

\section{Highlights:}

- Participants previously attended a driver education course that emphasises safe driving attitudes

- Participants were asked for their opinions about driver education and several psychosocial factors were measured

- Psychosocial factors influence young driver perceptions of driver education and training 


\section{Introduction and literature review}

Driver education and training

Young people are at increased risk of death and injury from motor vehicle crashes compared to older more experienced drivers (McCartt, Mayhew, Braitman, Ferguson, \& Simpson, 2009; Shults \& Williams, 2017). Driver education and training targeting young people is a common approach used around the world to enhance the skills and abilities of these novice drivers (Lonero, 2008), often with the intent of reducing young driver crash involvements. Driver training refers to instruction about specific skills (e.g. braking) while driver education refers to a more holistic process incorporating a wider range of information surrounding driving and road safety, although the terms are often used interchangeably (Beanland, Goode, Salmon, \& Lenné, 2013). Driver education can occur pre-and-post licensure and a wide variety of types of driver education have been developed which may include in-car skills training, classroombased activities (Raftery \& Wundersitz, 2011), or computer-based tasks aimed at specific skills development such as hazard perception (Young, Crundall, \& Chapman, 2017). Some jurisdictions, such as in the US, incorporate ongoing driver education and training into high school curriculums (Mayhew, 2007) while others have a mix of professional and informal training which is generally conducted by parents (Bates, Watson, \& King, 2014).

To date, most evaluations of professional driver education and training have found that it does not provide safety benefits for young drivers, over and above private instruction (Bates, Filtness, \& Watson, 2018; Beanland et al., 2013; Christie, 2001; Mayhew, 2007). However, there may be methodological issues with the evaluation research that has been conducted, particularly inadequate sample sizes (Bates et al., 2018; Peck, 2011). Driver education programs have been criticised for prioritising procedural skill-building without attending to attitudinal, motivational, and other independent differences that may influence young driver behaviour (Mayhew, Simpson, \& Robinson, 2002). Some driver education programs focusing on attitudinal factors have been developed which have so far demonstrated mixed results in terms of safety outcomes (Lewis, Fleiter, \& Smith, 2015; Senserrick \& Swinburne, 2001; White, Cunningham, \& Titchener, 2011).

\section{Goals for Driver Education Framework}

A major progression in driver education and training was the development of the Goals for Driver Education (GDE) framework (Hatakka, Keskinen, Gregersen, Glad, \& Hernetkoski, 2002; young drivers and driver education and training and aims to provide guidance for evaluating 
existing driver education programs and developing new programs (Hatakka et al., 2002). Taking previous hierarchical models of driving and using a social cognitive psychological base, the factors that driver educators should consider in young novice driver education are arranged into four levels. The focus of the GDE levels range from driving-specific and concrete to general and abstract. Individual differences that may affect driving are incorporated into the framework in the form of three person-specific factors which should be considered at each level of the hierarchy (see Table 1) (Peraaho et al., 2003).

Table 1

The twelve aspects of focus for driver education and training within the Goals for Driver Education with examples

\begin{tabular}{llll}
\hline & $\begin{array}{l}\text { Knowledge and } \\
\text { skills }\end{array}$ & $\begin{array}{l}\text { Risk-increasing } \\
\text { factors }\end{array}$ & $\begin{array}{l}\text { Self-evaluation and } \\
\text { awareness skills }\end{array}$ \\
\hline $\begin{array}{l}\text { Goals for life and skills } \\
\text { for living (Level Four) }\end{array}$ & $\begin{array}{l}\text { Knowledge of } \\
\text { personal } \\
\text { tendencies that } \\
\text { affect driving }\end{array}$ & $\begin{array}{l}\text { Non-acceptance of } \\
\text { social norms } \\
\text { regarding drug use }\end{array}$ & $\begin{array}{l}\text { Ability to recognise } \\
\text { impulses }\end{array}$ \\
\hline $\begin{array}{l}\text { Goals and contexts for } \\
\text { driving (Level Three) }\end{array}$ & Ability to plan trips & $\begin{array}{l}\text { Risks associated } \\
\text { with driver } \\
\text { condition }\end{array}$ & Personal planning skills \\
\hline Mastery of traffic & Safety margins & $\begin{array}{l}\text { Driving skill in } \\
\text { relation to weather } \\
\text { situations (Level Two) }\end{array}$ & $\begin{array}{l}\text { Awnareness of personal } \\
\text { driving style }\end{array}$ \\
\hline $\begin{array}{l}\text { Vehicle manoeuvring } \\
\text { (Level One) }\end{array}$ & $\begin{array}{l}\text { Non-declarative } \\
\text { knowledge of how } \\
\text { to operate car }\end{array}$ & $\begin{array}{l}\text { Insufficient } \\
\text { automatization of } \\
\text { psychomotor skills } \\
\text { for operating the } \\
\text { vehicle }\end{array}$ & $\begin{array}{l}\text { Realistic self- } \\
\text { evaluation of ability to } \\
\text { reverse park }\end{array}$ \\
\hline & & &
\end{tabular}

Adapted from Peraaho et al., 2003

There is some evidence that the GDE has been used as a basis for jurisdiction-based testing criteria and development of driver education curricula in Scandinavia (Henriksson, Stenlund, Sundström, \& Wiberg, 2007) and to analyse the driver education curriculum in Spain (Molina, García-Ros, \& Keskinen, 2014). However, it is difficult to ascertain how commonly the GDE has been used as a foundation for driver education programs or professional driving instruction, particularly outside of Europe, since this information is not always in the public domain. Nonetheless, it is worth noting that the framework is strongly advocated for by road safety researchers (e.g. Fisher \& Dorn, 2016). The GDE framework has been used in previous studies to compare the perceptions of driver educators and participants on what had been taught in a specific driver education course with the results suggesting that driver educators need to be more explicit when operating within the higher levels of the GDE framework 
(Rodwell et al., 2018) and to develop a higher-order instruction coding taxonomy for young drivers (Watson-Brown, Scott-Parker, \& Senserrick, 2018).

\section{Psychosocial influences on young driver behaviour}

While a large body of research has examined psychosocial influences on young driver behaviour, there does not appear to be any specific research investigating such influences in relation to young novice driver perceptions of education and training. Thus, we start by focussing on factors that are known to have an impact on risky driving behaviours by novice drivers.

A high proportion of young driver crashes most likely result from driving errors (Curry, Hafetz, Kallan, Winston, \& Durbin, 2011). However, a wide range of additional factors have been investigated as potential causes for the increased crash involvement of young people (Bates, Davey, Watson, King, \& Armstrong, 2014). These factors include biological, psychosocial, and developmental characteristics associated with adolescence and young adulthood (Dahl, 2008). Three psychosocial influences on young driver behaviour found to be important in the literature are personality factors (e.g. Lucidi et al., 2010), social norms (e.g. Merrikhpour \& Donmez, 2017), and attitudes (e.g. Musselwhite, 2006).

\section{Sensation-seeking, Normlessness, and Attitudes towards driving risk}

Sensation seeking is a personality trait characterised by the desire to have diverse, novel and impactful experiences and a readiness to take physical and social risks to have these experiences (Zuckerman, 2015 [1979]). Sensation seeking has been linked to risky driving among young people (Jonah, Thiessen, \& Au-Yeung, 2001), and has been found to be a better predictor of speeding behaviour than driving anger in a study of young French drivers (Delhomme, Chaurand, \& Paran, 2012). Trimpop and Kirkcaldy (1997) found that sensation seeking was an effective predictor of moving violations in a sample of young Canadian drivers and that correlates of sensation seeking were able to reliably discriminate between crashinvolved and non-crash involved drivers. Other studies suggest that sensation seeking may influence risky driving through other intervening variables (Dunlop \& Romer, 2010) or may also act as an intervening variable (Hatfield, Fernandes, \& Job, 2014). Clearly, trait sensation seeking has the potential to influence the risky behaviours engaged in by individuals including risky driving and may affect the way an individual engages with driver education.

Social norms constitute the expected social behaviours of a particular group, provide its definitional characteristics and facilitate group identity, function to direct group members in what to do in particular circumstances, and direct the sanctions that apply for deviating from these behaviours (McDonald \& Crandall, 2015). Given that there are explicit norms surrounding legal driving behaviour, normlessness has been connected with unsafe attitudes towards driving and increased propensity for breaking road rules, risky driving, and crash 
involvement (Nordfjærn \& Rundmo, 2013; Nordfjærn et al., 2014; Oltedal \& Rundmo, 2006; Ulleberg, 2001; Ulleberg \& Rundmo, 2003; Yang, Du, Qu, Gong, \& Sun, 2013). For example, in a recent study, normlessness was negatively related to positive attitudes to traffic safety (i.e., negative attitudes towards risky driving) in a large sample of Italian young, adult, and older drivers (Lucidi et al., 2019). In this study, the association between normlessness and positive attitudes to traffic safety was significantly stronger in young drivers than in older drivers. There was also a positive relationship between normlessness and driving violations in young and adult drivers but not older drivers in this sample. As young people often engage in professional driver education and training that involves instruction regarding road rules and appropriate legal driving behaviours, normlessness may influence how young drivers engage with this process.

A commonly accepted (Iversen, 2004) definition of an attitude is, "tendencies to evaluate an entity with some degree of favour or disfavour, ordinarily expressed in cognitive, affective and behavioural responses" (Eagly \& Chaiken, 1993). Risky attitudes in relation to young drivers have been conceptualised in several ways. These include attitudes towards: speeding (Whissell \& Bigelow, 2003); rule violations and carelessness of others (Iversen, 2004); acceptability of road rule violations and riding for fun (Chen, 2009; Ulleberg \& Rundmo, 2002); drink driving, seatbelt use and passenger behaviour (Harré, Brandt, \& Dawe, 2000).

Driver attitudes have been found to correlate with particular risky driving behaviours such as aggressive driving, speeding and intentions to break road rules (Waylen \& McKenna, 2008). A significant positive correlation was found by Ulleberg and Rundmo (2002) between attitudes towards risky driving activities (including a preference for breaking rules to maintain traffic flow) and self-reported involvement in risk taking driving behaviour and crashes, such that those with more positive attitudes reported greater involvement in risk taking and crashes. Iversen (2004) found that driver attitudes may be used as an easily assessable predictor of driver behaviour accounting for $53 \%$ of variance when predicting future driving behaviour, with less safe attitudes indicating riskier behaviour. Risky attitudes during the learner driver phase and after licensure are better predictors of dangerous driving than attitudes held before learning to drive (Rowe, Maughan, Gregory, \& Eley, 2013). More positive attitudes towards risky driving behaviours have been found in older teens when compared to younger (pre-learner) teens and in males when compared to females (Harré et al., 2000). Yagil (1998) found that young adult drivers have more positive attitudes towards risky driving behaviours than more experienced middle aged adults.

\section{The current study}

The current study sought to identify if psychosocial factors affect young people's perceptions regarding the benefits of driver education courses targeting pre-learners and learner drivers. This has potentially important implications for the design, content and implementation of 
more effective driver education and training programs especially for those that focus on attitudinal and motivational factors rather than procedural skills.

This study uses the GDE framework to explore these perceptions regarding the different levels of driver education and training. A range of psychosocial variables were selected for examination as a starting point for research in this area: thrill seeking, normlessness, attitudes towards risky driving and speeding. While thrill seeking and attitudes have been found to be influential in previous young driver research, the research team believed that normlessness has the potential to influence on the perceptions young people have of the benefits of driver education and training. Moreover, these variables are complementary in nature reflecting both relatively stable (e.g. personality factors) and malleable (e.g. attitudes) constructs as well as those influenced by individual level (e.g. thrill seeking) and social factors (e.g. normlessness).

\section{Method}

\section{Participants}

Participants were former students of a two-day driver education course containing both classroom and practical elements delivered in regional Queensland, Australia to high school students who were typically aged 16 or 17 years. Participants needed to be $17-19$ years and attended this course in the past three years. A sample of formally educated young drivers was used in order to ensure participants had an informed understanding and experience of driver education to reflect on. In total 905 potential participants were approached and there was a response rate of $18.0 \%$.

\section{Method}

Data collection occurred from February to March 2016. Potential participants were sent an email invitation to complete an anonymous online survey from a community-based driver education organisation. Each person who completed the survey, administered through the KeySurvey software, received an AUD\$10 shopping voucher incentive. The study received ethical approval (Queensland University of Technology ethics approval no. 1500001083). Data was analysed using SPSS version 24.

\section{Instruments}

The online survey consisted of demographic questions and eight scales. Four scales, designed for this study, measured perceptions regarding the benefits of education for pre-learner and learner drivers at each of the GDE levels (see Appendix A). Questions measuring attitudes towards driver education curriculum were developed by the research team and designed to align with each GDE person specific factor and level combination. Each of the four GDE levels were represented by three questions addressing the three person specific factors by way of a general statement and representative example. For example 'It would be/is beneficial for 
people on a learner licence or about to get a learner licence to receive feedback and learn how to judge for themselves their abilities in traffic situations, e.g. Testing knowledge of road rules, ability to adapt to weather conditions.' Responses were recorded on a 7 point Likert scale where 1 represented strongly disagree and 7 represented strongly agree. The Cronbach's alphas for each scale indicated strong levels of internal consistency (GDE Level 1: .79; GDE Level 2: .86; GDE Level 3: .84; GDE Level 4: .83). Responses to the GDE scales were used as the dependent variables in the analyses.

Additionally, the study included four independent variable scales measuring psychosocial factors: driver thrill seeking, normlessness, attitudes to driver risk taking and positive attitudes to speeding. Driver thrill seeking was measured using a previously adapted eight item subscale (Bates, Scott-Parker, Allen, \& Watson, 2016) from the Driver Behaviour Inventory (Matthews, Desmond, Joyner, Carcary, \& Gilliland, 1997). Higher scores on a seven point Likert scale (1 strongly disagree to 7 strongly agree) indicated higher thrill seeking tendencies. The Cronbach's alpha for the scale used in this study was .90 which is consistent with the .87 in Bates et al. (2016).

Normlessness was measured using the scale developed by Ulleberg and Rundmo (2003). The scale contained four items which in our study were measured on a seven point Likert scale. Higher scores indicated higher levels of normlessness. The Cronbach's alpha for this scale in the current study was .78 which is slightly higher than the .71 found by Ulleberg and Rundmo (2003).

The traffic flow vs rule obedience scale developed by Ulleberg and Rundmo (2003) which contained nine items and was adapted to have the same response format as the GDE questions was used. Within this study, it was labelled 'attitudes towards driver risk taking' so the meaning of scores on the scale were clearer. Items were focused on more general driving risk taking behaviours and included 'Sometimes it is necessary to take chances in the traffic' and 'There are many traffic rules which cannot be obeyed in order to keep up the traffic flow'. High scores indicated favouring traffic flow over rule obedience and hence high scores indicate a more positive attitude towards taking driving risks. Within this study, the Cronbach's alpha was .95. The Cronbach's alpha within Ulleberg and Rundmo (2003) was .87.

The positive attitudes towards speeding scale included five questions from Ulleberg and Rundmo (2003) measured on a seven point Likert scale. A higher score indicated a more supportive attitude towards speeding behaviour. This scale measured concepts that were more specific than those relating to attitudes towards driver related risk-taking, as all items focused on speeding. These items included 'If you have good skills, speeding is OK' and 'Driving 5 or 10 kilometres above the speed limit is ok because everyone does it.' The Cronbach's alpha for this scale within this study was .95 which is higher compared to when it has been used previously (84; Ulleberg \& Rundmo, 2003). 


\section{Results}

The data of 114 participants was included in the analyses. Of these, $69.3 \%(n=79)$ were female. The mean age was 17.9 years $(S D=0.9)$ and $94.7 \%(n=108)$ of participants were born in Australia. Most participants completed the driver education course while in their final year of school ( $n=57,50 \%$ ), although some completed it in the penultimate ( $n=40,35.1 \%$ ) or third last year of school ( $n=5,4.9 \%)$. Most participants $(n=84,73.7 \%)$ were still studying. Nearly two-thirds of the sample ( $n=71,62.3 \%$ ) were currently employed and, of these, $25.4 \%$ $(n=18)$ were employed full time, $19.7 \%(n=14)$ were employed part time and $54.9 \%(n=39)$ casually. Almost all participants ( $n=113,99.1 \%$ ) had obtained their learner drivers licence with the majority ( $n=88,77.2 \%$ ) doing so before they completed the driver education course.

Table 2 presents the means and standard deviations for the independent and dependent variables. A series of hierarchical regression analyses were used to identify the effect of psychosocial factors on the perceptions of young people of the benefits of learning various aspects of driving at each level of the GDE. Given the significant impact that age and gender have on driving behaviours and attitudes (Bates, Davey, et al., 2014; Shope, 2006), these variables were entered into the first step of the regression to control for their effects. Normlessness and sensation seeking were then entered at step 2 while attitudes towards aspects of driving were entered at step 3. This enabled an assessment of whether attitudes predicted perceptions over and above socio-demographic and the other psychosocial variables. The first regression predicted participants' perceptions of the benefits of education at Level 1 of the GDE, vehicle manoeuvring (table 3). Only predictors in the third step of the regression were significant and indicated that individuals with higher levels of thrill seeking $(p=.03)$ and those who had less positive attitudes towards speeding behaviour $(p=.02)$ believe that there were benefits of providing education to pre-learner and learner drivers regarding vehicle manoeuvring.

Table 2.

Descriptive statistics

\begin{tabular}{|c|c|c|c|c|c|}
\hline Personality/attitudes $^{1}$ & $M$ & $S D$ & GDE level $^{1}$ & $M$ & $S D$ \\
\hline Driver thrill seeking & 2.79 & 1.48 & GDE Level 1 & 6.48 & 0.76 \\
\hline Normlessness & 3.08 & 1.37 & GDE Level 2 & 6.55 & 0.67 \\
\hline $\begin{array}{l}\text { Attitudes to driver risk } \\
\text { taking }\end{array}$ & 5.95 & 1.06 & GDE Level 3 & 6.36 & 0.79 \\
\hline $\begin{array}{l}\text { Positive attitudes to } \\
\text { speeding }\end{array}$ & 2.10 & 1.48 & GDE Level 4 & 5.46 & 1.58 \\
\hline
\end{tabular}


Table 3.

Hierarchical Multiple Regression Predicting Perceptions of Benefits of Education at Level 1 of the GDE for pre-learner or learner drivers

\begin{tabular}{|c|c|c|c|c|c|c|}
\hline Variable & $B$ & SE B & $B$ & $s r^{2}$ & Adj. $R^{2}$ & $\mathrm{R}^{2}$ change \\
\hline \multicolumn{7}{|l|}{ Step 1} \\
\hline Age & .03 & .09 & .03 & .00 & & \\
\hline Gender & -.21 & .16 & -.14 & .02 & .00 & .02 \\
\hline \multicolumn{7}{|l|}{ Step 2} \\
\hline Age & .03 & .09 & .04 & .00 & & \\
\hline Gender & -.12 & .18 & -.08 & .00 & & \\
\hline Normlessness & .01 & .06 & .02 & .00 & & \\
\hline Thrill seeking & .06 & .06 & .13 & .01 & -.01 & .02 \\
\hline \multicolumn{7}{|l|}{ Step 3} \\
\hline Age & .01 & .09 & .01 & .00 & & \\
\hline Gender & -.09 & .17 & -.06 & .00 & & \\
\hline Normlessness & .08 & .07 & .16 & .02 & & \\
\hline Thrill seeking & .14 & .06 & $.29^{*}$ & .05 & & \\
\hline $\begin{array}{l}\text { Positive } \\
\text { attitudes to } \\
\text { speeding }\end{array}$ & -.15 & .07 & $-.31^{*}$ & .06 & & \\
\hline $\begin{array}{l}\text { Attitudes } \\
\text { towards } \\
\text { driver risk }\end{array}$ & .10 & .07 & .14 & .02 & .05 & $.08^{*}$ \\
\hline
\end{tabular}

Table 4 shows the results for perceptions of education at level 2 of the GDE, Mastery of traffic situations. The first and second steps, and the individual predictors within them, were not significant. In this regression, age, gender and normlessness were not related to participants' perceptions of education at GDE level 2. Participants who had more positive attitudes towards risky driving ( $p=.02)$ and had higher levels of thrill seeking $(p=.02)$ believed that being taught the skills required for driving in traffic was beneficial. Those who had less positive attitudes to speeding behaviour were more likely to think education at this level would be beneficial ( $p$ $=.02$ ). Together these variables explained 11 per cent of the variance regarding participants' perceptions of the benefits of education at the second level of the GDE. The inclusion of the positive attitudes to speeding and attitudes towards driver risk at Step 3 accounted for an additional 12 per cent of the unique variance explained in the benefits of education at level 2 of the GDE for pre-learner or learner drivers. 
Table 4.

312 Hierarchical Multiple Regression Predicting Perceptions of Benefits of Education at Level 2 of 313 the GDE for pre-learner or learner drivers

\begin{tabular}{|c|c|c|c|c|c|c|}
\hline Variable & $B$ & SE B & $b$ & $s r^{2}$ & Adj. $R^{2}$ & $\mathrm{R}^{2}$ change \\
\hline \multicolumn{7}{|l|}{ Step 1} \\
\hline Age & .02 & .07 & .03 & .00 & & \\
\hline Gender & -.21 & .12 & -.18 & .03 & .01 & .03 \\
\hline \multicolumn{7}{|l|}{ Step 2} \\
\hline Age & .03 & .07 & .04 & .00 & & \\
\hline Gender & -.15 & .14 & -.12 & .01 & & \\
\hline Normlessness & .03 & .05 & .06 & .00 & & \\
\hline Thrill seeking & .04 & .05 & .10 & .01 & .01 & .02 \\
\hline
\end{tabular}

Step 3

\begin{tabular}{|c|c|c|c|c|c|c|}
\hline Age & .00 & .07 & .00 & .00 & & \\
\hline Gender & -.14 & .13 & -.12 & .01 & & \\
\hline Normlessness & .08 & .05 & .20 & .03 & & \\
\hline Thrill seeking & .11 & .05 & $.29^{*}$ & .05 & & \\
\hline $\begin{array}{l}\text { Positive } \\
\text { attitudes to } \\
\text { speeding }\end{array}$ & -.12 & .05 & $-.32^{*}$ & .06 & & \\
\hline $\begin{array}{l}\text { Attitudes } \\
\text { towards } \\
\text { driver risk }\end{array}$ & -.13 & .05 & $-.32^{*}$ & .05 & .11 & $.12 * *$ \\
\hline
\end{tabular}

317 Table 5 shows the results for perceptions of education at level 3 of the GDE, learning about 318 the goals and context for driving. Only the third step was significant. In this analysis, both 319 normlessness $(p=.02)$ and thrill seeking $(p=.049)$ are significant. Individuals with higher 320 levels of normlessness and thrill seeking perceived that it was beneficial to teach pre-learner 321 and learner drivers aspects of education contained within level 3 of the GDE. Additionally, 322 those who had less positive attitudes towards speeding $(p=.02)$ and those with more positive 323 attitudes towards driver risk taking $(p<.001)$ perceived that it is beneficial to learn about this GDE level. This regression explained 24 per cent of the variance. 
Table 5.

Hierarchical Multiple Regression Predicting Perceptions of Benefits of Education at Level 3 of the GDE for pre-learner or learner drivers

\begin{tabular}{|c|c|c|c|c|c|c|}
\hline Variable & $B$ & SE B & b & $s r^{2}$ & Adj. $R^{2}$ & $R^{2}$ change \\
\hline \multicolumn{7}{|l|}{ Step 1} \\
\hline Age & .03 & .09 & .03 & .00 & & \\
\hline Gender & -.31 & 17 & -.19 & .04 & .02 & .04 \\
\hline \multicolumn{7}{|l|}{ Step 2} \\
\hline Age & .04 & .09 & .04 & .00 & & \\
\hline Gender & -.27 & 19 & -.17 & .02 & & \\
\hline Normlessness & .09 & .06 & .16 & .02 & & \\
\hline Thrill seeking & .00 & .06 & -.01 & .00 & .02 & .02 \\
\hline \multicolumn{7}{|l|}{ Step 3} \\
\hline Age & .01 & .08 & .01 & .00 & & \\
\hline Gender & -.29 & 16 & -.18 & .02 & & \\
\hline Normlessness & .15 & .06 & $.27^{*}$ & .05 & & \\
\hline Thrill seeking & .12 & .06 & $.23^{*}$ & .03 & & \\
\hline $\begin{array}{l}\text { Positive } \\
\text { attitudes to } \\
\text { speeding }\end{array}$ & -.15 & .06 & $-.29^{*}$ & .05 & & \\
\hline $\begin{array}{l}\text { Attitudes } \\
\text { towards } \\
\text { driver risk }\end{array}$ & .32 & . 07 & $.43^{* * *}$ & 16 & .24 & $.23^{* * *}$ \\
\hline
\end{tabular}

Finally, table 6, shows the factors that predict participants' perceptions of the benefits of learning about the broader context contained within GDE level 4, goals and skills for living. Gender was a significant predictor $(p=.02)$ within the first step of the regression but this disappeared in the second step of the regression. The third step of the regression explained $76 \%$ of the variance. This is probably because of the high positive correlation between the attitudes towards driver risk scale and the GDE4 scale $(r=.87)$. The only significant predictor in the third step is participants' attitudes towards driver risk taking $(p<.001)$ which explained $70 \%$ of the unique variance in the perceptions of benefits of education at Level 4 of the GDE for pre-learner or learner drivers. Those with more positive attitudes towards driver risk taking believe that it is beneficial to be taught about the aspects of driving contained within level 4 of the GDE. Overall, these regressions highlight that different psychosocial factors affect participants' perceptions of the benefits of learning about various aspects of driving contained within GDE. 
Table 6.

Hierarchical Multiple Regression Predicting Perceptions of Benefits of Education at Level 4 of the GDE for pre-learner or learner drivers

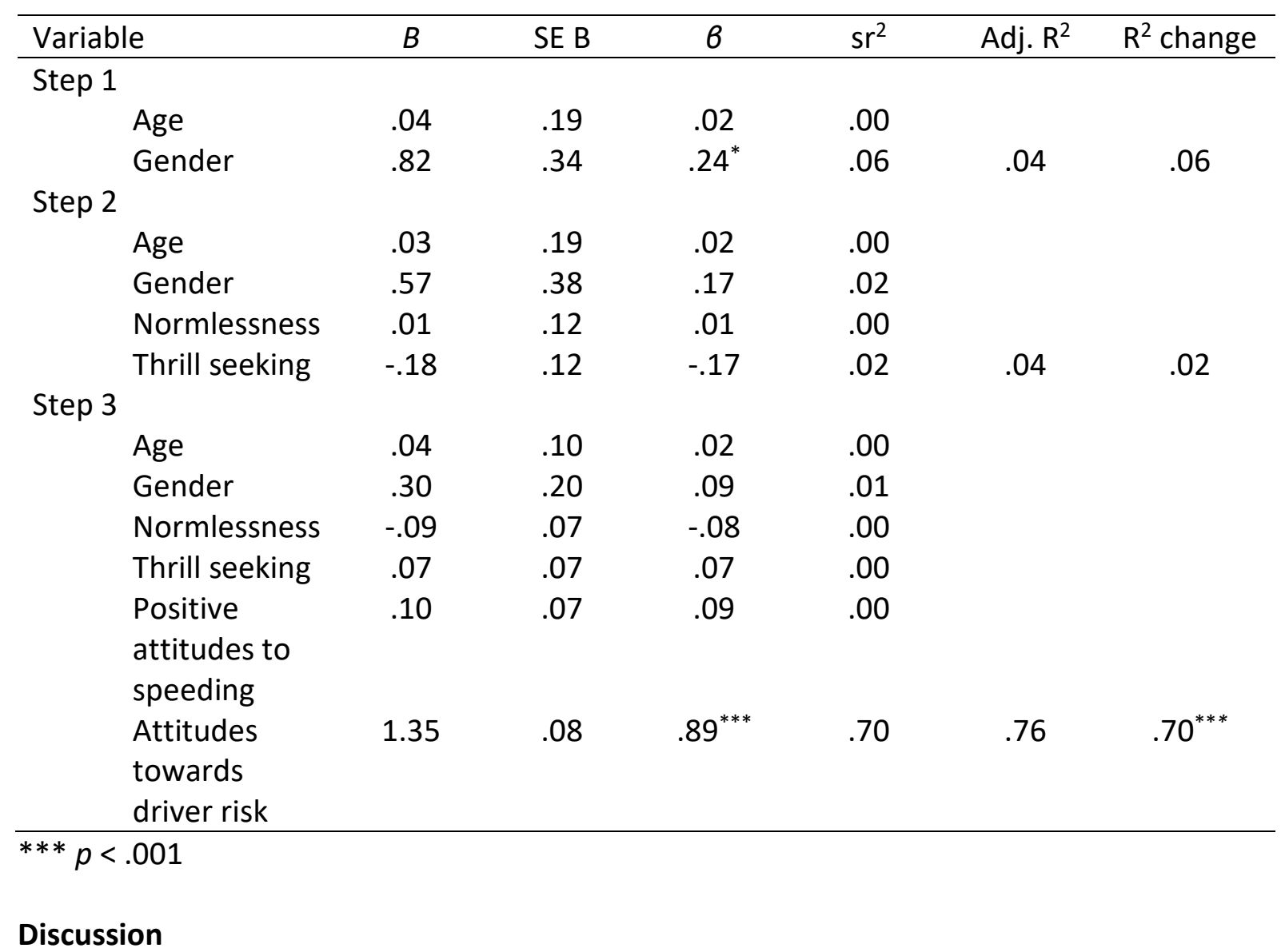

This study suggests that young drivers' psychosocial factors impact on their perceptions of the education they receive, in terms of what they believe would be beneficial for young people to learn while at the pre-learner and learner stages. Higher levels of thrill seeking was a significant predictor of the benefits associated with education targeting the lower three levels of the GDE framework where there was a clear link to driving, but not in relation to Goals for Life (Level 4). Given that sensation seeking has been linked to risky driving behaviours (e.g. Jonah, 1997; Jonah et al., 2001), one possible reason why those who have higher levels of this trait believe that it is beneficial to be taught vehicle control skills, mastering traffic situations and the goals and contexts for driving is because they believe that these skills are critical for driving, suggesting a focus on the performance-related aspects of the task. This is consistent with research suggesting those who receive certain types of driver education and training (skid control) becoming over-confident but less safe (Katila, Keskinen, Hatakka, \& Laapotti, 2004).

Having more negative attitudes to speeding predicted that participants thought it more beneficial for learners and pre-learners to undertake driver education at the lower levels of the GDE framework. This suggests that participants thought it more beneficial for learners 
and pre-learners to be taught performance-related aspects of driving (i.e. vehicle control skills, mastering traffic situations and the goals and contexts for driving) when they held less positive attitudes to speeding. While driver attitudes are correlated with various driver behaviours (Waylen \& McKenna, 2008), the relationship between attitudes and speeding may be more complex. Fleiter and Watson (2006) surveyed 320 Queensland drivers aged between 17 and 79 years $(M=37.25 ; S D=15.28)$ regarding their attitudes to speeding and their selfreported speeding behaviour. They identified that, despite participants reporting that travelling faster than the posted speed limit was not worth the risks involved, more than half indicated that they preferred to drive faster than a $100 \mathrm{~km} / \mathrm{hr}$ speed limit suggesting an apparent paradox. The findings from the current study suggest that those who hold less positive attitudes to speeding are more focused on ensuring that education includes information at the lower levels of the GDE framework where discussions about adhering to the speed limit and the benefits of doing so are likely to take place.

Holding a more positive attitude to driver risk taking predicted that the participants thought it beneficial for new drivers to be taught at the three highest levels of the GDE framework: mastering traffic situations, goals and contexts for driving and goals for life and skills for living. The proportion of variance that this factor at the highest level of the GDE explains may be related to the high correlation between the two scales suggesting that the broader concepts within attitudes to driver risk taking are part of the goals for life and skills for living. The highest level of the GDE includes skills such as having a knowledge of their personal tendencies and an ability to recognise their own impulses, which at face value, do appear strongly related to attitudes to risk taking. Holding favourable attitudes to taking risks while driving may also mean that young drivers think that it is beneficial for them to master traffic situations and understand the reasons for driving in order to compensate for their risk taking. Likewise, a higher level of normlessness predicted that it was beneficial to learn about specific trip, context and goals rather than the information contained in the lower levels of the GDE. Previous research has identified that normlessness is linked with an increased propensity to break the road rules, risky driving and crash involvement (Nordfjærn \& Rundmo, 2013; Nordfjærn et al., 2014; Oltedal \& Rundmo, 2006; Ulleberg, 2001; Ulleberg \& Rundmo, 2003; Yang et al., 2013). Thus, those who have higher levels of normlessness may need to be aware of the more abstract factors related to driving.

Overall, this study indicates that psychosocial factors do affect young driver perceptions of professional driver education and training which has the aim of teaching young people safe and appropriate driving behaviours. This is important as this could inform the future design of traditional driver education and training courses which, in turn, could improve the efficacy. However, the study did not identify if these factors affect the outcomes of the driver education and training programs whether this be changes in attitudes, behaviours or crash rates. This is an area for research in the future. 
A limitation of this research is the use of a sample from one education facility that had undertaken one type of course. This limits the ability to generalise the findings to other populations and courses. Additionally, the response rate for this study is relatively low (18\%). Future research should consider examining the psychosocial factors that affect perceptions of driver education and training that uses a different sampling method and recruits from a wider range of courses.

A strength of this study is the use of the GDE to guide our understanding of driver education and training. This framework was designed to provide guidance and structure to the evaluation of existing and development of new driver education programs (Hatakka et al., 2002). However, the framework has had limited applications within a research context with some exceptions more recently (Rodwell et al., 2018; Watson-Brown et al., 2018), although it does appear to have been used to guide the development of some interventions (Rowden, Watson, Wishart, \& Schonfeld, 2009). Thus the application and inclusion of the GDE framework within the research is a strength and highlights the potential increase in explanatory power which results in applying a framework in this field.

Driver education programs, in many cases, appear to focus on building knowledge and skills without taking into account psychological and other factors that may influence the way information is interpreted by students. However, given that psychosocial factors influence perceptions about the benefits of learning at the various levels of the GDE framework, there may be a need for driver educators to consider presenting information in different ways to influence these groups. For instance, having a higher level of sensation seeking or a less positive attitude to speeding predicted that participants reported learning vehicle control skills (level 1 of the GDE framework) as being beneficial. These two psychosocial factors appear to create conflicting levels of the perceived benefits regarding learning vehicle control skills. Thus, while it is important for driver educators to stress the importance of vehicle control skills, it is essential that they communicate the need for skill development at all levels of the GDE framework. This is necessary to ensure that novice drivers do not either overestimate or under-estimate the role of vehicle control skills in safe driving. In particular, it is important to avoid creating over-confidence among those drivers who have higher levels of sensation seeking. In this respect, they could clearly indicate to new drivers that those with a higher level of sensation seeking are at an increased risk of being involved in a crash.

An example of how the findings of this research could be applied to the design and/or delivery of driver education programs relates to the possibility of utilising more flexible delivery options. For instance, online programs could ask participants questions to ascertain their attitudes and other psychosocial factors in the early components of the intervention. The responses to these early questions could then indicate the amount of emphasis an online program places on the various modules that are delivered. By doing this, participants would experience an intervention that was more customised to fit their needs. It may also be possible to use driving simulators the same way within driver education programs. However, 
it appears that young drivers and driver educators are currently ambivalent about the use of simulators in driver education (Rodwell et al., 2019). Mirman (2019) appears to support the idea of more customised approaches when she states that there are different groups of novices at varying levels of risk throughout the licensure period and there is a need to take the risk levels of these sub-groups into account when designing interventions.

The findings from this research also suggest that if driver educators are presenting material from Level 4 of the GDE framework, goals and skills of living, they may need to link this more directly back to driving to demonstrate its relevance to participants. This was also found in Rodwell et al. (2018). This is because the mean scores suggest that participants considered the lower three levels of the framework more beneficial, possibly because these are more explicitly linked to driving. Given that material that is presented with a high level of engagement appears to affect perceptions of driver education (Lennon \& Bates, 2015), educators should focus on ensuring this occurs across all levels of the framework.

\section{Conclusion}

The findings of this study indicate that the variables of interest (driver thrill seeking, normlessness, attitudes towards driver risk taking and positive attitudes to speeding) mainly affect the three lower levels (vehicle manoeuvring, mastery of traffic situations and goals and contexts for driving) of the GDE framework. However, the research indicates that psychosocial factors affect these beliefs with higher levels of sensation seeking and less positive attitudes to speeding predicting that it is beneficial for new drivers to be taught skills at these levels of the GDE framework. Higher levels of normlessness predicted that it was beneficial for new drivers to be taught about specific trip, context and goals which is level 3 of the GDE framework. Attitudes towards risky driving explained a significant proportion of variance for level 4 of the framework. This is probably because there is a strong relationship between attitudes towards risky driving and the goals for life and skills for living including having a knowledge of personal tendencies (such as risk taking) and an ability to recognise impulses.

Our findings indicate that we may need to consider how education is approached. Rather than using one method to teach all participants, there may be a need to personalise education as much as possible to take into account various psychosocial factors. There may also be a need to explicitly link information from the higher levels of the GDE framework to the driving context to help participants view this information as beneficial. While this study has focussed on perceptions of driver education, future research could consider how psychosocial factors affect the outcomes of driver education such as behaviours and crashes. 


\begin{tabular}{|c|c|}
\hline $\begin{array}{l}\text { GDE } \\
\text { level } \\
\text { and } \\
\text { person } \\
\text { factor }\end{array}$ & $\begin{array}{l}\text { Thinking about driver education in general, regardless of whether or not you were } \\
\text { taught these things, please answer the following: } \\
\text { It would be/is beneficial for people on a learner licence or about to get a learner } \\
\text { licence to: }\end{array}$ \\
\hline $1 \mathrm{~K}$ & $\begin{array}{l}\text { arn about the practical knowledge and skills of vehicle manoeuvring and } \\
\text { aintenance e.g. How to control the direction of the car, check tyre pressure }\end{array}$ \\
\hline $1 R$ & $\begin{array}{l}\text { arn about the risks associated with the way they drive a car e.g. Poor braking } \\
\text { chnique, steering }\end{array}$ \\
\hline $1 S$ & $\begin{array}{l}\text { receive feedback and learn how to judge for themselves their driving abilities to } \\
\text { manoeuvre a car and how to manage associated risks }\end{array}$ \\
\hline $2 K$ & $\begin{array}{l}\text { learn about traffic rules and safe driving practices e.g. Safe following } \\
\text { (hangback)distance, using traffic lights safely }\end{array}$ \\
\hline $2 R$ & $\begin{array}{l}\text { learn about risks associated with traffic situations e.g. Vulnerable pedestrians, } \\
\text { heavy rain }\end{array}$ \\
\hline $2 S$ & $\begin{array}{l}\text { receive feedback and learn how to judge for themselves their abilities in traffic } \\
\text { situations, e.g. Testing knowledge of road rules, ability to adapt to weather } \\
\text { conditions }\end{array}$ \\
\hline $3 \mathrm{~K}$ & $\begin{array}{l}\text { learn about goals drivers have when deciding to drive and factors about driving } \\
\text { that affect their decisions e.g. Pressure to impress friends, planning a suitable } \\
\text { route for a trip }\end{array}$ \\
\hline $3 R$ & $\begin{array}{l}\text { learn about risks associated with goals drivers make e.g. Driving while tired, } \\
\text { planning in advance not to drive when going to a party }\end{array}$ \\
\hline $3 S$ & $\begin{array}{l}\text { receive feedback and learn how to judge their own ability manage risks and use } \\
\text { skills when making driving decisions e.g. Ability (or inability) to identify when over } \\
\text { the legal alcohol limit, ability to stand up to peer pressure. }\end{array}$ \\
\hline $4 K$ & $\begin{array}{l}\text { learn about the wider context of life that can influencing driving e.g. Self-control, } \\
\text { employment requirements, personal values }\end{array}$ \\
\hline $4 R$ & $\begin{array}{l}\text { learn about how the wider context of life can increase risks when driving e.g. } \\
\text { Medical problems, feeling a need to rebel, expressing frustration or anger }\end{array}$ \\
\hline $4 S$ & $\begin{array}{l}\text { receive feedback and learn how to judge their own ability to manage risks in their } \\
\text { personal context of life e.g. A tendency to take risks, personal values about safety }\end{array}$ \\
\hline
\end{tabular}




\section{References}

Bates, L., Davey, J., Watson, B., King, M., \& Armstrong, K. (2014). Factors contributing to young driver crashes: A review. Sultan Qaboos University Medical Journal, 14(3), 297-305.

Bates, L., Filtness, A., \& Watson, B. (2018). Driver Education and Licensing Programs. In D. Lord \& S. Washington (Eds.), Safe Mobility: Background, Challenges and Solutions. Bingley: Emerald Group Publishing.

Bates, L., Scott-Parker, B., Allen, S., \& Watson, B. (2016). Young driver perceptions of police traffic enforcement and self reported driving offences. Policing: An International Journal of Police Strategies and Management, 39(4), 723-739. doi:http://dx.doi.org/10.1108/PIJPSM-10$\underline{2015-0121}$

Bates, L., Watson, B., \& King, M. J. (2014). The role of parents and non-parents in the supervision of learner drivers in Australia. Accident Analysis \& Prevention, 70, 40-45. doi:http://dx.doi.org/10.1016/j.aap.2014.03.004

Beanland, V., Goode, N., Salmon, P. M., \& Lenné, M. G. (2013). Is there a case for driver training? A review of the efficacy of pre- and post-licence driver training. Safety Science, 51(1), 127-137. doi:http://dx.doi.org/10.1016/i.ssci.2012.06.021

Chen, C.-F. (2009). Personality, safety attitudes and risky driving behaviors-Evidence from young Taiwanese motorcyclists. Accident Analysis \& Prevention, 41(5), 963-968. doi:10.1016/j.aap.2009.05.013

Christie, R. (2001). The effectiveness of driver training as a road safety measure: An international review of the literature. In 2001 Road Safety Research, Policing and Education Conference. Adelaide.

Curry, A. E., Hafetz, J., Kallan, M. J., Winston, F. K., \& Durbin, D. R. (2011). Prevalence of teen driver errors leading to serious motor vehicle crashes. Accident Analysis \& Prevention, 43(4), 12851290. doi:10.1016/j.aap.2010.10.019

Dahl, R. E. (2008). Biological, developmental, and neurobehavioral Ffactors relevant to adolescent driving risks. American Journal of Preventive Medicine, 35(3, Supplement), S278-S284. doi:10.1016/j.amepre.2008.06.013

Delhomme, P., Chaurand, N., \& Paran, F. (2012). Personality predictors of speeding in young drivers: Anger vs. sensation seeking. Transportation Research Part F: Traffic Psychology and Behaviour, 15(6), 654-666. doi:https://doi.org/10.1016/i.trf.2012.06.006

Dunlop, S. M., \& Romer, D. (2010). Adolescent and Young Adult Crash Risk: Sensation Seeking, Substance Use Propensity and Substance Use Behaviors. Journal of Adolescent Health, 46(1), 90-92. doi:https://doi.org/10.1016/i.jadohealth.2009.06.005

Eagly, A. H., \& Chaiken, S. (1993). The psychology of attitudes: Harcourt Brace Jovanovich College Publishers.

Fisher, D. L., \& Dorn, L. (2016). The Training and Education of Novice Teen Drivers In D. L. Fisher, J. Caird, W. Horrey, \& L. Trick (Eds.), Handbook of Teen and Novice Drivers : Research, Practice, Policy, and Directions (pp. 270-289). Milton, United States: CRC Press.

Fleiter, J., \& Watson, B. (2006). The speed paradox: the misalignment between driver attitudes and speeding behaviour. Journal of the Australasian College of Road Safety, 17(2), 23-30.

Harré, N., Brandt, T., \& Dawe, M. (2000). The Development of Risky Driving in Adolescence. Journal of Safety Research, 31(4), 185-194. doi:10.1016/S0022-4375(00)00035-9

Hatakka, M., Keskinen, E., Gregersen, N. P., Glad, A., \& Hernetkoski, K. (2002). From control of the vehicle to personal self-control: Broadening the perspectives to driver education. Transportation Research Part F: Traffic Psychology and Behaviour, 5(3), 201-215.

Hatfield, J., Fernandes, R., \& Job, R. F. S. (2014). Thrill and Adventure Seeking as a modifier of the relationship of perceived risk with risky driving among young drivers. Accident Analysis \& Prevention, 62(Supplement C), 223-229. doi:https://doi.org/10.1016/i.aap.2013.09.028 
Henriksson, W., Stenlund, T., Sundström, A., \& Wiberg, M. (2007). The GDE-model as a guide in driver training and testing.: Proceedings from the conference, Umeå, May 7-8, 2007.

Iversen, H. (2004). Risk-taking attitudes and risky driving behaviour. Transportation Research Part F: Traffic Psychology and Behaviour, 7(3), 135-150.

Jonah, B. (1997). Sensation seeking and risky driving: A review and synthesis of the literature. Accident Analysis \& Prevention, 29(5), 651-665.

Jonah, B., Thiessen, R., \& Au-Yeung, E. (2001). Sensation seeking, risky driving and behavioral adaptation. Accident Analysis \& Prevention, 33(5), 679-684.

Katila, A., Keskinen, E., Hatakka, M., \& Laapotti, S. (2004). Does increased confidence among novice drivers imply a decrease in safety? The effects of skid training on slippery road accidents. Accident Analysis \& Prevention, 36(4), 543-550.

Lennon, A., \& Bates, L. (2015). Examining novice education: What can we learn from a qualitative evaluation of a compulsory program delivered to both mature-age and young pre-learner licence drivers? Paper presented at the Australasian Road Safety Conference, Gold Coast, Australia.

Lewis, I., Fleiter, J., \& Smith, J. (2015). Students' responses to the RACQ Docudrama program. Paper presented at the Australasian Road Safety Conference, Gold Coast, Queensland.

Lonero, L. P. (2008). Trends in Driver Education and Training. American Journal of Preventive Medicine, 35(3), S316-S323. doi:10.1016/j.amepre.2008.06.023

Lucidi, F., Giannini, A. M., Sgalla, R., Mallia, L., Devoto, A., \& Reichmann, S. (2010). Young novice driver subtypes: Relationship to driving violations, errors and lapses. Accident Analysis \& Prevention, 42(6), 1689-1696. doi:10.1016/j.aap.2010.04.008

Lucidi, F., Girelli, L., Chirico, A., Alivernini, F., Cozzolino, M., Violani, C., \& Mallia, L. (2019). Personality traits and attitudes toward traffic safety predict risky behavior across young, adult, and older drivers. Frontiers in Psychology, 10(536). doi:10.3389/fpsyg.2019.00536

Matthews, G., Desmond, P., Joyner, L., Carcary, B., \& Gilliland, K. (1997). A comprehensive questionnaire measure of driver stress and affect. Traffic and transport psychology: Theory and application, 317-324.

Mayhew, D. (2007). Driver education and graduated licensing in North America: Past, present, and future. Journal of Safety Research, 38(2), 229-235.

Mayhew, D., Simpson, H., \& Robinson, A. (2002). The safety value of driver education and training. Injury Prevention, 8(Suppl 2), ii3-ii8. doi:10.1136/ip.8.suppl_2.ii3

McCartt, A., Mayhew, D., Braitman, K., Ferguson, S. A., \& Simpson, H. (2009). Effects of age and experience on young driver crashes: Review of recent literature. Traffic Injury Prevention, 10(3), 209-219.

McDonald, R., \& Crandall, C. (2015). Social norms and social influence. Current Opinion in Behavioral Sciences, 3, 147-151.

Merrikhpour, M., \& Donmez, B. (2017). Designing feedback to mitigate teen distracted driving: A social norms approach. Accident Analysis \& Prevention, 104(Supplement C), 185-194. doi:10.1016/j.aap.2017.04.016

Mirman, J. (2019). A dynamical systems perspective on driver behavior. Transportation Research Part F: Traffic Psychology and Behaviour, 63, 193-203. doi:doi.org/10.1016/j.trf.2019.04.010

Molina, J., García-Ros, R., \& Keskinen, E. (2014). Implementation of the driver training curriculum in Spain: An analysis based on the Goals for Driver Education (GDE) framework. Transportation Research Part F: Traffic Psychology and Behaviour, 26, Part A, 28-37. doi:10.1016/j.trf.2014.06.005

Musselwhite, C. (2006). Attitudes towards vehicle driving behaviour: Categorising and contextualising risk. Accident Analysis \& Prevention, 38(2), 324-334. doi:10.1016/j.aap.2005.10.003 
Nordfjærn, T., \& Rundmo, T. (2013). Road Traffic Safety Beliefs and Driver Behaviors Among Personality Subtypes of Drivers in the Norwegian Population. Traffic Injury Prevention, 14(7), 690-696. doi:10.1080/15389588.2012.759655

Nordfjærn, T., Şimşekoğlu, Ö., Zavareh, M. F., Hezaveh, A. M., Mamdoohi, A. R., \& Rundmo, T. (2014). Road traffic culture and personality traits related to traffic safety in Turkish and Iranian samples. Safety Science, 66(Supplement C), 36-46. doi:https://doi.org/10.1016/i.ssci.2014.02.004

Oltedal, S., \& Rundmo, T. (2006). The effects of personality and gender on risky driving behaviour and accident involvement. Safety Science, 44(7), 621-628. doi:https://doi.org/10.1016/j.ssci.2005.12.003

Peck, R. C. (2011). Do driver training programs reduce crashes and traffic violations? - A critical examination of the literature IATSS Research, 34(63-71).

Peraaho, M., Keskinen, E., \& Hatakka, M. (2003). Driver competence in a hierarchical perspective: Implications for driver education. In. Finland: University of Turku, Traffic Research.

Raftery, S. J., \& Wundersitz, L. N. (2011). The efficacy of road safety education in schools: A review of current approaches. Retrieved from Adelaide:

Rodwell, D., Hawkins, A., Haworth, N., Larue, G., Bates, L., \& Filtness, A. (2018). A mixed-method study of driver education informed by the goals for driver education: Do young drivers and educators agree what was taught? Safety Science, 108, 140-148.

Rodwell, D., Hawkins, A., Haworth, N., Larue, G., Bates, L., \& Filtness, A. (2019). What do driver educators and young drivers think about driving simulators? A qualitative draw-and-talk study. Transportation Research Part F: Traffic Psychology and Behaviour, 62, 282-293. doi:doi.org/10.1016/j.trf.2019.01.008

Rowden, P., Watson, B., Wishart, D., \& Schonfeld, C. (2009). Changing motorcycle rider safety attitudes and motives for risk taking: Process evalautio of a rider training intervention. Paper presented at the Australasian Road Safety Research, Policing and Education Conference, Sydney.

Rowe, R., Maughan, B., Gregory, A. M., \& Eley, T. C. (2013). The development of risky attitudes from pre-driving to fully-qualified driving. Injury prevention, injuryprev-2012-040551.

Senserrick, T., \& Swinburne, G. C. (2001). Evaluation of an Insight Driver-Training Program for Young Drivers (186). Retrieved from Melbourne: Folder 1 - Number 29

Shope, J. T. (2006). Influences on youthful driving behavior and their potential for guiding interventions to reduce crashes. Injury Prevention, 12(suppl_1), i9-14.

Shults, R. A., \& Williams, A. F. (2017). Trends in teen driver licensure, driving patterns and crash involvement in the United States, 2006-2015. Journal of Safety Research, 62(Supplement C), 181-184. doi:10.1016/j.jsr.2017.06.013

Trimpop, R., \& Kirkcaldy, B. (1997). Personality predictors of driving accidents. Personality and Individual Differences, 23(1), 147-152. doi:https://doi.org/10.1016/S0191-8869(97)00017-2

Ulleberg, P. (2001). Personality subtypes of young drivers. Transportation Research Part F: Traffic Psychology and Behaviour, 4(4), 279-297. doi:10.1016/S1369-8478(01)00029-8

Ulleberg, P., \& Rundmo, T. (2002). Risk-taking attitudes among young drivers: The psychometric qualities and dimesnionality of an instrument to measure young drivers' risk-taking attitudes. Scandinavian Journal of Psychology, 43(3), 227-237.

Ulleberg, P., \& Rundmo, T. (2003). Personality, attitudes and risk perception as predictors of risky driving behaviour among young drivers. Safety Science, 41(5), 427-443. doi:10.1016/SO9257535(01)00077-7

Watson-Brown, N., Scott-Parker, B., \& Senserrick, T. M. (2018). Development of a higher-order instruction coding taxonomy for observational data: Initial application to professional driving instruction. Applied Ergonomics, 70, 88-97. doi:10.1016/j.apergo.2018.02.016

Waylen, A. E., \& McKenna, F. P. (2008). Risky attitudes towards road use in pre-drivers. Accident Analysis \& Prevention, 40(3), 905-911. 
Whissell, R. W., \& Bigelow, B. J. (2003). The speeding attitude scale and the role of sensation seeking in profiling young drivers at risk. Risk analysis, 23(4), 811-820.

White, M. J., Cunningham, L. C., \& Titchener, K. (2011). Young drivers' optimism bias for accident risk and driving skill: Accountability and insight experience manipulations. Accident Analysis \& Prevention, 43(4), 1309-1315. doi:http://dx.doi.org/10.1016/j.aap.2011.01.013

Yagil, D. (1998). Gender and age-related differences in attitudes toward traffic laws and traffic violations. Transportation Research Part F: Traffic Psychology and Behaviour, 1(2), 123-135. doi:10.1016/S1369-8478(98)00010-2

Yang, J., Du, F., Qu, W., Gong, Z., \& Sun, X. (2013). Effects of Personality on Risky Driving Behavior and Accident Involvement for Chinese Drivers. Traffic Injury Prevention, 14(6), 565-571. doi:10.1080/15389588.2012.748903

Young, A. H., Crundall, D., \& Chapman, P. (2017). Commentary driver training: Effects of commentary exposure, practice and production on hazard perception and eye movements. Accident Analysis \& Prevention, 101, 1-10. doi:http://dx.doi.org/10.1016/j.aap.2017.01.007

Zuckerman, M. (2015 [1979]). Sensation seeking: beyond the optimal level of arousal. New York: Psychology Press. 